Research Journal of Medical Sciences 6 (4): 154-158, 2012

ISSN: $1815-9346$

(C) Medwell Journals, 2012

\title{
Determinants of Rehabilitation Services Staffs' Job Satisfaction (By Effort Reward Imbalance) and Variations in Teaching, Profit Making and Non Profit Hospitals
}

\author{
${ }^{1}$ I. Devreux, ${ }^{2} \mathrm{~A}$. Jacquerye, ${ }^{2} \mathrm{~F}$. Kittel, ${ }^{1} \mathrm{~K}$. Mamdouh and ${ }^{3} \mathrm{~B}$. Al-Awa \\ ${ }^{1}$ Department of Physical Therapy, College of Applied Medical Sciences, \\ King Abdul Aziz University, Jeddah, Kingdom of Saudi Arabia \\ ${ }^{2}$ Ecole de Sante Publique, Universite Libre de Bruxelles, Brussels, Belgium \\ ${ }^{3}$ King Abdul Aziz University Hospital, Jeddah, Kingdom of Saudi Arabia
}

\begin{abstract}
To evaluate the level of work satisfaction based on the Effort-Reward Imbalance Model of staff working in rehabilitation services of different categories (in teaching, profit making and non-profit making hospitals). Participants were 166 therapists and assistants working in the Departments of Physical, Occupational and Respiratory Therapy from 10 hospital centers classified per three different categories in the Jeddah area. Effort-Reward Imbalance and staff satisfaction with intrinsic and extrinsic variables were measured by a self-administered questionnaire. There is a significant difference of level of job satisfaction measured by effort and reward imbalance between the therapists and assistant therapists working in the teaching, private or non-profit making health care facilities. In comparison by hospital type, the surveyed rehabilitation staffs presented a higher mean effort-reward imbalance in the teaching hospitals but higher job satisfaction with their salary, their perception of salary comparatively to others, yearly performance appraisal grading and affective commitment. In the rehabilitation services of non-profit making hospitals, the surveyed therapists and assistant therapists had the lowest mean Effort-Reward Imbalance ratio explained by their satisfaction with the variables of patient/staff ratio and emotional attachment to the organization. In the profit making healthcare facilities, the surveyed staffs are comparatively more satisfied with the variables of doctors' respect, involvement in quality improvement or educational lectures and transportation to/from work. Rehabilitation services staffs working in teaching hospitals and profit making hospitals had in general a higher effort-reward imbalance ratio with work stress and low satisfaction in work compared to the non-profit hospital facilities. Job satisfaction of rehabilitation staff varies per hospital type and mission of the health care facility.
\end{abstract}

Key words: Job satisfaction, Effort-Reward Imbalance, rehabilitation services, hospital type, health care

\section{INTRODUCTION}

Physical rehabilitation services in Saudi Arabia are found in health care facilities throughout the kingdom which can be categorized in private or profit making, public or non-profit making and teaching hospitals. While the public sector plays an essential role in the management and regulation of curative services, the private healthcare sector has an increased role in the provision of rehabilitation care. However, therapists and assistant therapists working in the rehabilitation services may have different perceptions of satisfaction about their work depending on their working conditions and situation. The interest of the research is to identify the possible variables that could affect job satisfaction in the three healthcare facilities categories. Accordingly, the main aim of this study is to identify components of job satisfaction based on the Effort and Reward Imbalance Model and compare the job satisfaction level of employees working in the different types of health care facilities in the Jeddah area. Job satisfaction has been defined as the match between an individual's expectations and the perceived reality of the job as a whole (Smith et al., 1969). Other theorists have viewed job satisfaction as a bi-dimensional concept consisting of intrinsic and extrinsic dimensions (Herzberg et al., 1959) and distinguish between satisfiers and dissatisfiers. Previous research has studied the effects of sociodemographic factors and work-related factors (work activities, working hours, salary and positions) on job satisfaction. Demographic factors such as age, sex and educational levels have been seen determining the level

Corresponding Author: I. Devreux, Department of Physical Therapy, College of Applied Medical Sciences,

King Abdul Aziz University, Jeddah, Kingdom of Saudi Arabia 
of job satisfaction though some research showed contradictory results (Al-Ahmadi, 2002). The intrinsic factors of work are seen to be affecting motivation and job satisfaction in research. Some researchers have found that physiotherapist agreed that the work is challenging in a positive sense and enabled them to use their skills and abilities with enough independence and autonomy in decision making (Speakman et al., 1996) but also found that physiotherapists were overloaded and mentally stressed.

In particular, dissatisfied employees are likely to leave their jobs (Dogan, 2009; Campo et al., 2009). Thus, the understanding of employee job satisfaction and its contributing variables are important for any organization to exist and prosper (Mrayyan, 2005). Hospital administrators have noticed the importance of job satisfaction on a variety of organizational variables (Chu et al., 2003). These variables of organization differ from one hospital type to another depending on the motivating aspects and the mission of the healthcare facility and may be reflected on the staffs' work inputs and work-role outputs (Sousa-Poza and Sousa-Poza, 2000) and on the effort-reward imbalance at work (Siegrist, 2002).

\section{MATERIALS AND METHODS}

The survey is concerned with the study of a population of 222 rehabilitation professionals (therapists and assistants in physical therapy, occupational therapy and respiratory therapy that are employed on a full time basis) practicing in the various public and private health care settings of the Jeddah area. The therapists addressed by the survey are working in university hospitals or public hospitals related to the Ministry of Health as well as in private health care facilities, hospitals, rehabilitation centers and large outpatient clinics. This research utilizes a prospective two dimensional survey approach (studying the patients and staff satisfaction) by questionnaires to the targeted populations in randomly selected hospitals of the Jeddah area and received a $75 \%$ of answering rate. The questionnaires are at first resuming the sociodemographic information of the therapists and assistants. A second section of the survey questionnaire evaluates the effort and reward imbalance score and overcommitment of the staff and a third section is based on some specific questions related to the practice of work in rehabilitation (Siegrist, 1996). With reference to the literature review a questionnaire for rehabilitation services personnel was made and included validated approach to measure psycho-social work stress based on the HighEffort/Low-RewardImbalance (ERI) (Siegrist, 1996) and an associated over-commitment scale which sum both in total twenty three questions without modifications from the original standardized questionnaire. The Effort Reward Imbalance ratio is calculated and if this score is higher than 1 it indicates an imbalance between the effort given and the reward received by the professional. The aim of utilizing the ERI evaluation score is that it is possible to correlate results and compare them with other health care facilities. The last part of the effort-reward imbalance questionnaire is including questions related to the affective commitment of the person to the organization.

The third part of the staff job satisfaction survey questionnaire is based on the Minnesota Job Satisfaction Survey questionnaire (Weiss et al., 1967) and additional questions were designed to identify specific variables potentially affecting the work of physical therapists or technicians such as teamwork and communication, work environment and equipments and the involvement in the quality improvement process. It is based on the literature review presenting the following variables of staff satisfaction in rehabilitation services: workload, autonomy of practice, professional growth, working relationship, environment of care, salary and benefits, professional role and overcommitment. The questionnaires' results and data are first encoded in an Excel format and SPSS program for analysis (Statistical Package for Social Sciences, Version 16). Missing values of $>50 \%$ per domain are considered as invalid. Descriptive statistics and correlations analyses were made $\mathrm{p}<0.05$ are considered as significant.

\section{RESULTS AND DISCUSSION}

The mean (SD) effort and reward imbalance ratio for 166 surveyed rehabilitation staff is of $1.34(0.51)$. It is significantly different between hospital categories $(\mathrm{p}=0.001)$ and with a Bonferroni correction test between the teaching and non-profit hospitals $(\mathrm{p} 2 \leq 0.001)$ as well as between the profit making and non-profit making hospitals ( $33 \leq 0.002)$. However, between the teaching and profit making category the difference with the Bonferroni correction is not statistically significant (Fig. 1). Table 1 shows the frequencies of positive answers by I agree and I strongly agree to the questions of satisfaction in work per hospital category. Out of 56 questions on variables of job satisfaction, 10 show a significant difference within categories after applying cross-tabulation analysis and the Kruskall-Wallis test. More precisely, results are significantly different between the teaching hospitals and the nonprofit hospitals ( $2 \leq 0.005)$ concerning the satisfaction with the patient/therapist ratio where globally $48.8 \%$ of the therapists are in average satisfied with their job and more specifically $58.5 \%$ of the therapists in the 
Res. J.Med. Sci., 6(4): 154-158, 2012

\begin{tabular}{|c|c|c|c|c|c|c|c|c|}
\hline \multirow[b]{2}{*}{ Variables of satisfaction } & \multicolumn{2}{|c|}{ Teaching hospital } & \multicolumn{2}{|c|}{ Profit making hospital } & \multicolumn{2}{|c|}{ Non profit hospital } & \multirow[b]{2}{*}{$\mathrm{p}$-value } & \multirow[b]{2}{*}{ Kruskal-Wallis test } \\
\hline & $\mathrm{n}=36$ & $\%$ & $\mathrm{n}=45$ & $\%$ & $\mathrm{n}=82$ & $\%$ & & \\
\hline Average patient-therapist ratio & 11 & 30.6 & 21 & 45.7 & 48 & 58.5 & 0.018 & $\mathrm{p} 2 \leq 0.005^{*}$ \\
\hline Salary and benefits & 16 & 45.7 & 8 & 17.8 & 22 & 26.8 & 0.021 & $\mathrm{p} 1 \leq 0.007^{*}$ \\
\hline Comparative salary & 16 & 45.7 & 9 & 19.6 & 18 & 22.2 & 0.014 & $\begin{array}{l}\mathrm{p} 1 \leq 0.012^{*} \\
\mathrm{p} 2 \leq 0.011^{*}\end{array}$ \\
\hline Transp ortation & 19 & 57.6 & 28 & 65.1 & 23 & 31.5 & 0.001 & $\begin{array}{l}\mathrm{p} 2 \leq 0.011^{*} \\
\mathrm{p} 3 \leq 0.000^{*}\end{array}$ \\
\hline
\end{tabular}

Table 2: Percentage per hospital category of significant positive answers of job satisfaction compared by hospital category (Part 2) ( $\mathrm{n}=163)$

\begin{tabular}{|c|c|c|c|c|c|c|c|c|}
\hline \multirow[b]{2}{*}{ Variables of satisfaction } & \multicolumn{2}{|c|}{ Teaching hospital } & \multicolumn{2}{|c|}{ Profit making hospital } & \multicolumn{2}{|c|}{ Non profit hospital } & \multirow[b]{2}{*}{$\mathrm{p}$-value } & \multirow[b]{2}{*}{ Kruskal-Wallis test } \\
\hline & $\mathrm{n}=36$ & $\%$ & $\mathrm{n}=45$ & $\%$ & $\mathrm{n}=82$ & $\%$ & & \\
\hline Yearly performance evaluation & 29 & 85.3 & 30 & 65.2 & 45 & 54.9 & 0.008 & $\mathrm{p} 2 \leq 0.002^{*}$ \\
\hline Doctors and other staff respect & 22 & 61.1 & 37 & 80.4 & 45 & 54.9 & 0.015 & $\mathrm{p} 3 \leq 0.004^{*}$ \\
\hline $\begin{array}{l}\text { Orientation to infection control } \\
\text { policies }\end{array}$ & 27 & 75.0 & 36 & 78.3 & 44 & 53.7 & 0.008 & $\mathrm{p} 3 \leq 0.006^{*}$ \\
\hline $\begin{array}{l}\text { Educational lectures in quality } \\
\text { management }\end{array}$ & 15 & 41.7 & 60 & 65.2 & 37 & 45.1 & 0.050 & - \\
\hline Feeling like part of the family & 4 & 11.1 & 6 & 13.3 & 25 & 30.9 & 0.017 & - \\
\hline Feeling emotionally attached & 9 & 25.0 & 5 & 11.1 & 26 & 31.7 & 0.037 & $\mathrm{p} 3 \leq 0.010^{*}$ \\
\hline
\end{tabular}

p1 $=$ Teaching and profit hospitals $\mathrm{p} 2=$ Teaching and non-profit hospitals $\mathrm{p} 3=$ Profit and non-profit hospitals; ${ }^{*}$ Significance remains after Bonferroni correction

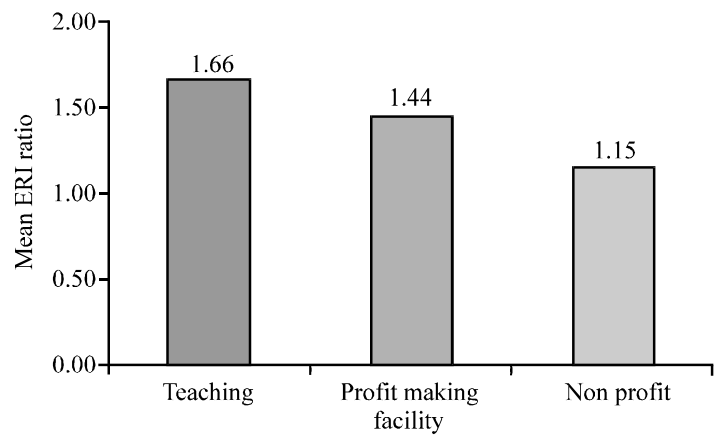

Fig. 1: Mean ERI ratio of rehabilitation staff per hospital category $(\mathrm{n}=166)$

public sector. Concerning the salary and benefits satisfaction, there is a difference between the teaching and profit hospitals with a much higher percentage of satisfaction in the teaching hospitals compared to the nonprofit hospitals. Comparatively, there is a significant difference between the teaching and profit making hospitals and between the non-profit hospitals for the comparative salary satisfaction. The teaching hospitals are having a higher frequency of positive answers compared to the other hospital categories regarding the perception of their salary in comparison to the ones in other hospitals. However, the Bonferroni analysis for non-profit and profit making hospitals does not conclude to a significant difference about this subject. The satisfaction with transportation has shown a significant difference between hospital categories which could be linked to the different type of nationalities and positions as foreign and junior staff felt this aspect as important to them. After a Bonferroni correction test, all previously mentioned differences remained except for the salary and benefits between the teaching and nonprofit hospitals and for comparative salary between profit and nonprofit making hospitals (Table 2).

From the results, the non-profit hospital categ ory has the lowest frequency of positive answers compared to the other hospital categories for the presented variables such as yearly feedback on performance, doctors/staffs' respect and orientation to infection control policies. For these pre-cited variables, the teaching hospital staffs have expressed more satisfaction excepted with the doctors/other staff respect which is higher in the nonprofit hospitals. Satisfaction in educational lectures in quality management is expressed for $65.2 \%$ of the staffs in the profit hospitals while the lowest level of satisfaction is in the teaching hospital group (for $41.7 \%$ ). Satisfaction with an emotional attachment and the feeling as part of a family in the organization is higher in the nonprofit hospitals with a percentage of 31 and $30 \%$ of positive answers per hospital category. The rehabilitation staffs' satisfaction with a feeling of emotional attachment appears to be less $(11 \%)$ in the nonprofit hospitals than in other categories.

The mean effort and reward imbalance ratio of the rehabilitation services staff is significantly different between hospital categories $(\mathrm{p} \leq 0.001)$. In comparison to the hospital types, staff satisfaction measured by mean ERI ratio $(1.66 ; \mathrm{p} \leq 0.001)$ is in average lower in the teaching hospitals but satisfaction is higher with regards to the salary $(\mathrm{p} \leq 0.007)$, perception of the salary compared to others $(\mathrm{p} \leq 0.012)$, the yearly performance appraisal 
( $\mathrm{p} \leq 0.002)$ and affective commitment score. In the nonprofit making hospitals, the average ERI ratio is lower $(p \leq 0.001)$ and satisfaction is the highest with the variables of patient/staff ratio and feeling emotionally attached to the organization $(p \leq 0.010)$. In the profit making hospitals, rehabilitation services staff are comparatively more satisfied with the variables of doctors respect $(\mathrm{p} \leq 0.004)$, involvement in quality improvement or educational lectures $(p \leq 0.030)$ and transportation modalities $(p \leq 0.001)$.

From the survey, it appears that there is a higher ERI ratio in the teaching hospitals category with a lower value in the profit making hospital category. The lowest mean ERI ratio is found in the nonprofit hospital category where the lowest job stress is in average expressed. The positive satisfaction answers of rehabilitation services staffs concerning job satisfaction variables have been compared from one hospital category to another. Results confirm the importance of the workload as intrinsic variable significantly affecting job satisfaction of rehabilitation services staff. Concerning the average patient/therapist ratio satisfaction, it appears that the staffs are in general more satisfied in the public hospitals where previous data have found that the effective average number of patients per therapist per day is less compared to the other sectors.

Less than one third of the staffs are satisfied with their salary and benefits and with their perceived comparative salary. This situation is especially expressed by the therapists working in the private healthcare facilities who are effectively less paid than in the teaching hospitals. Results are consistent to previous research made amongst other healthcare professionals in the region which identify the salary and benefits as significant extrinsic variables related to job satisfaction (Al-Ahmadi, 2002; Shah et al., 2000). Significantly higher reasons to satisfaction in work are seen for the variables of doctors and colleagues respect in the private hospitals who apparently work very closely together with the referring physicians. Another factor explaining this aspect is the smaller sizes of the private facilities promoting a tight link in the referral process and in the patient management.

A strong emotional attachment and feeling as part of the organization tends to be more marked in the public hospitals. Underlying differences are due to the type of contracts (more permanent) and the proportion of Saudi nationals employed in this sector being naturally more attached to their environment compared to foreign staffs. Possibilities of job advancement and professional recognition have also been outlined as important determinants of staff satisfaction and are consistent with findings of other research (Eker et al., 2004; Wittig et al.,
2003). Educational lectures and quality management orientation are appreciated by a comparatively higher number of staffs working in the profit making hospitals for whom educational lectures helps them to improve their professional skills and knowledge in a very competitive work environment. Differences of staff satisfaction with the yearly performance appraisals between hospitals' types suppose that it is strongly related to supervisors' demand of a high quantitative output and increased productivity as aimed in profit making facilities.

\section{CONCLUSION}

Rehabilitation services staffs working in teaching hospitals and profit making hospitals had in general a higher Effort-Reward Imbalance ratio with work stress and low satisfaction in work compared to the non-profit hospital facilities. In comparison by hospital type, the surveyed rehabilitation staffs in the teaching hospitals presented a higher job satisfaction with their salary, their perception of salary comparatively to others, yearly performance appraisal grading and affective commitment to the organization. In the rehabilitation services of nonprofit making hospitals, the surveyed therapists and assistant therapists had the lowest mean Effort-Reward Imbalance ratio explained by their satisfaction with the variables of patient/staff ratio and emotional attachment to the organization. In the surveyed profit making healthcare facilities however, rehabilitation services staffs are comparatively more satisfied with the variables of doctors' respect, involvement in quality improvement or educational lectures and transportation to/from their work place. Job satisfaction of rehabilitation staff varies per hospital type and the specific mission of the health care facilities.

\section{REFERENCES}

Al-Ahmadi, H., 2002. Job satisfaction of nurses in Ministry of Health Hospitals in Riyadh, Saudi Arabia. Saudi Med. J., 23: 645-650.

Campo, M.A., S. Weiser and K.L. Koenig, 2009. Job strain in physical therapists. Phys. Ther., 89: 946-956.

Chu, C.I., H.M. Hsu, J.L. Price and J.Y. Lee, 2003. Job satisfaction of hospital nurses: An empirical test of a causal model in Taiwan. Int. Nurs. Rev., 50: 176-182.

Dogan, H., 2009. A comparative study for employee job satisfaction in Aydin municipality and Nazilli municipality. Ege Acad. Rev., 9: 423-433.

Eker, L., E.H. Tuzun, A. Daskapan and O. Surenkok, 2004. Predictors of job satisfaction among physiotherapists in Turkey. J. Occup. Health, 46: 500-505. 
Herzberg, F., B. Mausner and B.B. Snyderman, 1959. The Motivation to Work. John Wiley and Sons Inc., New York, USA., ISBN: 9781560006343, pp: 143-159.

Mrayyan, M.T., 2005. Nurse job satisfaction and retention: Comparing public to private hospitals in Jordan. J. Nurs. Manage., 13: 40-50.

Shah, M.A., R.I. Chowdhury, N. Al-Enezi and N.M. Shah, 2000. Determinants of job satisfaction among selected care providers in Kuwait. J. Allied Health, 30: $68-74$.

Siegrist, J., 1996. Adverse health effects of high-effort/ low-reward conditions. J. Occup. Health Psychol., 1: 27-41.

Siegrist, J., 2002. Effort-Reward Imbalance at Work and Health. In: Historical and Current Perspectives on Stress and Health: Research in Occupational Stress and Well Being, Perrewe, P. and D. Ganster (Eds.). Vol. 2, Emerald Group Publishing Ltd., New York, USA., ISBN: 978-0-76230-970-2, pp: 261-291.
Smith, P.C., L.M. Kendall and C.L. Hulin, 1969. The Measurement of Satisfaction in Work and Retirement: A Strategy for the Study of Attitudes. Rand McNally, Chicago, Pages: 186.

Sousa-Poza, A. and A.A. Sousa-Poza, 2000. Well-being at work: A cross sectional analysis of the levels and determinants of job satisfaction. J. Socio-Econ., 29: $517-538$.

Speakman, H.G.B., J.M. Pleasant and G.B. Sutton, 1996. The job satisfaction of physical therapists. Physiother. Res. Int., 1: 247-254.

Weiss, D.J., R.V. Dawis, G.W. England and L.H. Lofquist, 1967. Manual for minnesota satisfaction questionnaire. Work Adjustment Project, Industrial Relations Center, University of Minnesota.

Wittig, P.G., L. Tilton-Weaver, B.N. Patry and C.A. Mateer, 2003. Variables related to job satisfaction among professional care providers working in brain injury rehabilitation. Disabil. Rehabil., 25: 97-106. 